\title{
BUILDING ISLAND RESILIENCE THROUGH THE ENERGY, WATER, FOOD NEXUS
}

Jennifer Daw and Sherry Stout

National Renewable Energy Laboratory

Produced under direction of the Government of Australia, Department of Environment and Energy by the National Renewable Energy Laboratory (NREL) under Work for Others Agreement number FIA-15-1808.

NREL/TP-7A40-74747

September 2019 


\section{BUILDING ISLAND RESILIENCE THROUGH THE ENERGY, WATER, FOOD NEXUS}

Jennifer Daw and Sherry Stout

National Renewable Energy Laboratory

Produced under direction of the Government of Australia, Department of Environment and Energy by the National Renewable Energy Laboratory (NREL) under Work for Others Agreement number FIA-15-1808.

NREL/TP-7A40-74747

September 2019 


\begin{abstract}
NOTICE
This manuscript has been authored by employees of the Alliance for Sustainable Energy, LLC ("Alliance") under Contract No. DE-AC36-08GO28308 with the U.S. Department of Energy ("DOE”).

This report was prepared as an account of work sponsored by an agency of the United States government. Neither the United States government nor any agency thereof, nor any of their employees, makes any warranty, express or implied, or assumes any legal liability or responsibility for the accuracy, completeness, or usefulness of any information, apparatus, product, or process disclosed, or represents that its use would not infringe privately owned rights. Reference herein to any specific commercial product, process, or service by trade name, trademark, manufacturer, or otherwise does not necessarily constitute or imply its endorsement, recommendation, or favoring by the United States government or any agency thereof. The views and opinions of authors expressed herein do not necessarily state or reflect those of the United States government or any agency thereof.
\end{abstract}




\section{Acknowledgements}

The authors would like to thank Fred Cuvalay, CEO of Statia Utility Company, for sharing insights and information on Statia's solar and energy storage park, which helped inform the development of this report. We also thank Alicen Kandt from the National Renewable Energy Laboratory and Jennifer Leisch from the U.S. Agency for International Development for their review of the report.

This work was supported by the Government of Australia Department of Environment and Energy and the United States Department of Energy through the Clean Energy Solutions Center, an initiative of the Clean Energy Ministerial. 


\section{List of Acronyms}

DER distributed energy resources

EWF

FEMA

GAO

energy, water, and food systems

IPCC

Federal Emergency Management Agency

U.S. Government Accountability Office

Intergovernmental Panel on Climate Change

MVA

megavolt-ampere

$\mathrm{MWh}$

$\mathrm{MW}_{\mathrm{p}}$

NREL

PV

STUCO

UNDP

megawatt-hour

megawatt peak

National Renewable Energy Laboratory

photovoltaic

Statia Utility Company

United Nations Development Program 


\section{Table of Contents}

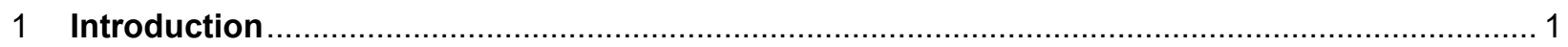

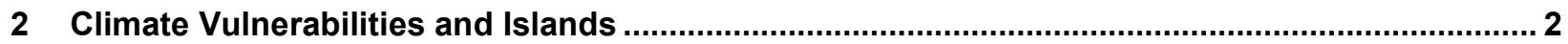

2.1 Island Energy, Water, and Food Systems ................................................................... 2

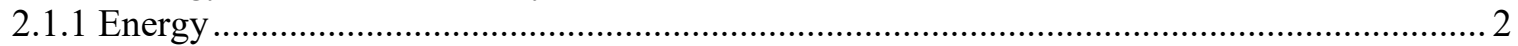

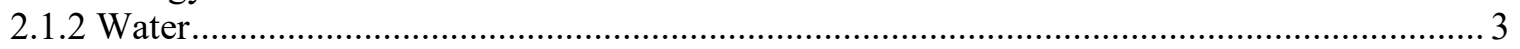

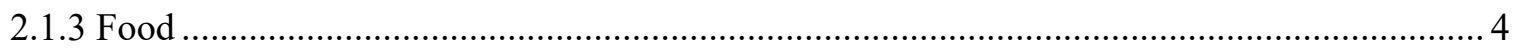

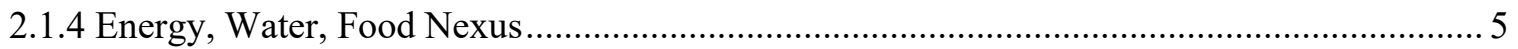

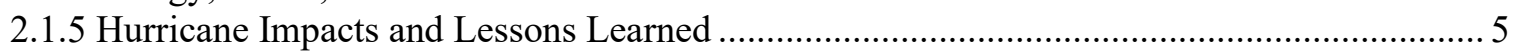

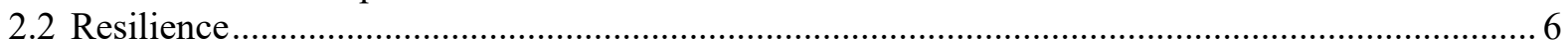

3 Case Study: St. Eustatius' Solar and Energy Storage Park ................................................... 7

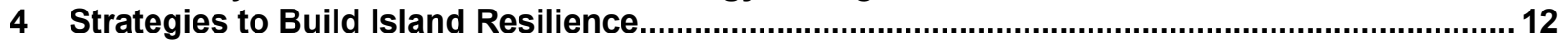

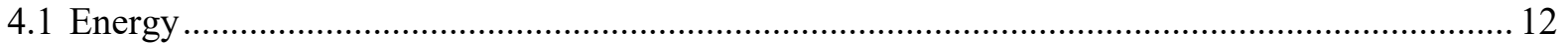

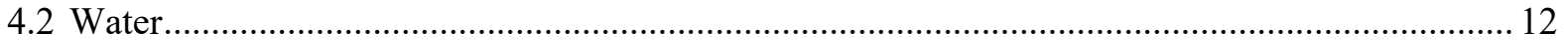

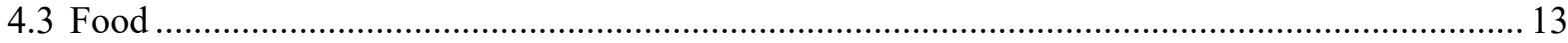

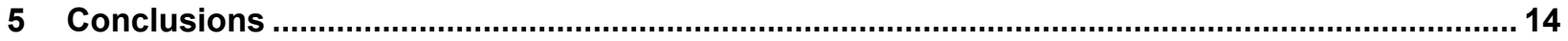

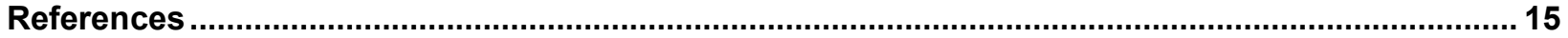




\section{List of Figures}

Figure 1. Water, population, primary energy, and carbon dioxide emission percentage growth rate, 1900-2040.

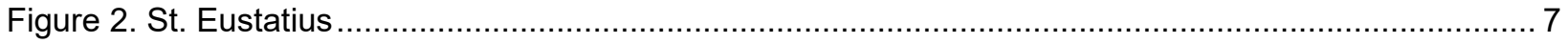

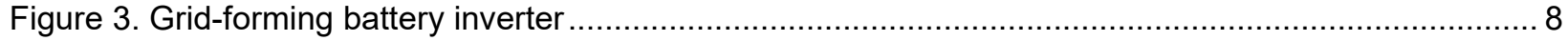

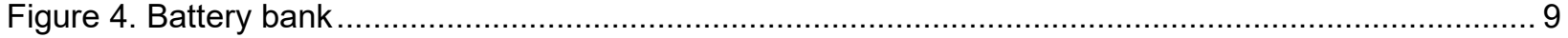

Figure 5. Typical day operations with diesel generators off........................................................... 9

Figure 6. Statia solar and energy park before and after Hurricane Irma ............................................ 10

Figure 7. Novel mounting height of solar panels at Statia solar and energy park .................................. 11

Figure 8. Rainwater-harvesting gutters mounted to PV array .......................................................... 11 


\section{Introduction}

The Western Hemisphere, including the Caribbean and Central America, experienced unprecedented extreme events in 2017, accounting for $83 \%$ of overall losses and $93 \%$ of insured losses from weather-related disasters worldwide that year (Löw 2018). Islands are particularly vulnerable to a range of climate-related hazards and threats, including sea level rise and the increasing intensity and frequency of extreme weather events (UN 1994). Given their disconnected nature, islands experience distinct logistical challenges when recovering from natural disasters, particularly in the continuity of basic services. Recent extreme events, such as Hurricanes Irma and Maria, have highlighted weaknesses in island energy, water, and food (EWF) systems as a result of utility outages, shipping delays, devastation of natural resources, and subsequent impacts on the economy. These events have challenged islands to improve their resilience, adopt integrated strategies that promote EWF security, and promote socioeconomic prosperity.

Island nations and territories are isolated by nature and are often limited in local resources. This creates a strong dependency on the import of many basic goods and materials across all sectors. A changing climate and extreme natural events have adverse effects on supply chains, posing undue burdens on these nations to meet the basic needs of their citizens and support economic growth. In the Caribbean, natural disasters have brought to light the importance and limited resilience these islands have for the continuity of basic services such as EWF supply, representing a significant threat to their way of life, as many islands lack adaptive capacity to recover from these disasters.

Historically, islands relied on local resources to meet their needs - harvesting rainwater or using groundwater sources for drinking water, burning available fuel sources for heat, and growing indigenous crops. Global shipping networks have fostered greater reliance on imported goods, resulting in reliance on fuel imports and reduced cultivation of indigenous foods. Many island economies have also grown to rely on tourism and service industries. Disaster events dramatically impact both supply chains and travel to islands, highlighting the need to build more resilience across these systems.

Considering these challenges, the island of St. Eustatius (Statia) devised an innovative approach to reduce its exposure to external supply disruptions and natural disasters while strengthening its resilience. Statia's solar and energy storage park is the first of its kind in the Caribbean, providing reliable energy, community agriculture, and harvested rainwater for irrigation. Using the proven example of Statia, this report provides strategies for enhancing resilience across the EWF nexus in island contexts. These integrated approaches are an example for other island states and territories of how to prepare for and recover from extreme events, while also providing innovative solutions to sustainably meet the growing demand for energy, water, and food resources. 


\section{Climate Vulnerabilities and Islands}

Island nations face unique and often significant climate-related threats. According to the United Nations Development Program (UNDP), "the difficulties that all countries face in effectively coping with climate change impacts are exacerbated in small island developing states because of their small geographical area, isolation and exposure" (UNDP 2010). Each island has unique climate risks, and "their high diversity in both physical and human attributes and their response to climate-related drivers means that climate change impacts, vulnerability, and adaptation will be variable from one island region to another and between countries in the same region" (Nurse et al. 2014). The Caribbean is naturally susceptible to a wide range of natural hazards, including floods, droughts, cyclones, pests, and diseases (Trotman 2012). Climate projections show increased risks and challenges for islands, with predictions of sea-level rise, increased occurrence and intensity of cyclones, increasing air and sea surface temperatures, and changing rainfall patterns (Nurse et al. 2014). The Intergovernmental Panel on Climate Change (IPCC) identifies a range of impacts associated with tropical and extratropical cyclone effects on small islands, including to island morphology (e.g., erosion, accretion, flooding, floodplain changes, landslides), ecosystems and natural resources (e.g., coral reef damage, soil salination, saltwater intrusion into freshwater), island livelihoods (e.g., destruction of subsistence crops and commercial agriculture, decreased fish production, losses to aquaculture and tourism), and island settlements and infrastructure (e.g., destruction of buildings and houses; damage to transport, water, energy, and health and safety infrastructure; and loss of cultural assets) (Nurse et al. 2014). Based on one IPCC climate change scenario for the Caribbean, the World Bank estimates the total annual impacts of potential climate change on 20 Caribbean Community countries (ca. 2080) to be US $\$ 11.2$ billion, or approximately $11.3 \%$ of the countries' combined annual gross domestic product (Toba 2009).

According to the National Intelligence Council, as the projected impacts of climate change go beyond physical stresses on resources,

... more extreme weather, water and soil stress, and food insecurity will disrupt societies. Sea-level rise, ocean acidification, glacial melt, and pollution will change living patterns. Tensions over climate change will grow. Increased travel and poor health infrastructure will make infectious diseases harder to manage. These trends will converge at an unprecedented pace to make governing and cooperation harder and to change the nature of power - fundamentally altering the global landscape. (National Intelligence Council 2017)

These changes go beyond physical effects on people and the environment by also affecting the viability of local economies.

\subsection{Island Energy, Water, and Food Systems}

\subsubsection{Energy}

While historically islands have relied almost exclusively on imported fossil fuels for energy generation, many have increased their use of renewable energy sources and adopted aggressive renewable energy goals in recent years. Importing fossil fuel creates energy prices on islands that are as volatile as the fuel market on which they rely. This, in turn, can create economic uncertainty for citizens, businesses, and potential investors. The mix of price volatility, imported fuel, and challenges associated with running small, islanded grids creates generally higher prices of electricity on islands when compared to larger grid systems. For example, in 2015, the average cost of residential electricity in the United States was \$0.127/kWh (EIA 2019), whereas Puerto Rico’s 
average residential rate was $\$ 0.24 / \mathrm{kWh}$, and the Caribbean regional average was $\$ 0.33 / \mathrm{kWh}$ (Energy Transition Initiative 2015). This high cost of power can negatively affect opportunities for economic development in island communities; however, this high cost of power can incentivize the use of renewable energy in lieu of outside fuel supplies, because the levelized cost of energy from renewable sources can be more advantageous for island systems.

The remote nature of islands makes their energy systems particularly vulnerable to disruption. Use of imported fuel can cause energy shortages when fuel deliveries are hindered for any reason (Ali and Wulandari 2008). Supply chain disruptions, particularly those in the wake of extreme events, cause unique burdens to islands that rely on fuel imports. These events have ripple effects on the provision of basic services, such as electricity, water, food, transportation, and effective governance. The challenging logistics of island nations can also inhibit recovery and aid agencies' efforts to bring in emergency supplies after a major event.

Islands are also limited in their options for increasing energy resilience. Small island nations have a limited ability to spatially diversify their energy systems. Climate threats - such as large stormsrarely affect an entire continent-based power network; however, it is not uncommon for large storms to fully envelop small island nations, impacting the entire power network. This can hinder system flexibility during or immediately following a major event.

Islands are unique, and the energy needs of their citizens can differ from those in larger continental nations. In the Caribbean, for example, residential electricity loads tend to be smaller, because construction methods often incorporate natural ventilation into design, and residents rely more on single-room, rather than central, air-conditioning units. On the other hand, space-conditioning loads in the commercial sector tend to be high to dehumidify occupied space. This is especially true of tourism-related energy loads. Industrial loads of island nations tend to be less diversified and more reliant on a few key industries, resulting in industrial energy load profiles unique to each island nation; however, many of the industrial loads found in island nations are dependent on consistent, high-quality power and can be severely impacted by power fluctuations or outages.

\subsubsection{Water}

Historically, islands have relied on rainwater and groundwater collection from freshwater lenses for freshwater supplies (Bailey et al. 2018; Chen et al. 2015). But changes in rainfall patterns, increases in severe storms, sea-level rise, and saltwater intrusion threaten many of these traditional water sources, which can add to "poverty, social tension, environmental degradation, ineffectual leadership, gender inequality, and weak political institutions - contributing to social disruptions that can prompt state failures" (National Intelligence Council 2017).

Pressures from a changing climate, population growth, and tourism are increasing the demand for fresh water in small island nations, particularly in regions with poor water quality or water scarcity. Desalination of sea and brackish water is a viable solution to address the issue of water scarcity and the growing demand for water; however, the energy implications of these technologies must be weighed against their widespread adoption. While seawater is an abundant resource for islands, its use for drinking water creates a significant shift in energy demand for water treatment, often increasing reliance on imported fuels and creating greater vulnerability to supply chain disruptions.

Figure 1 demonstrates this substantial projected growth, with an anticipated 1,000\% increase in water withdrawals and 500\% increase in primary energy consumption anticipated by the year 2040 
worldwide. These projections underscore the critical importance of making efficient use of both energy and water resources, particularly in island communities.

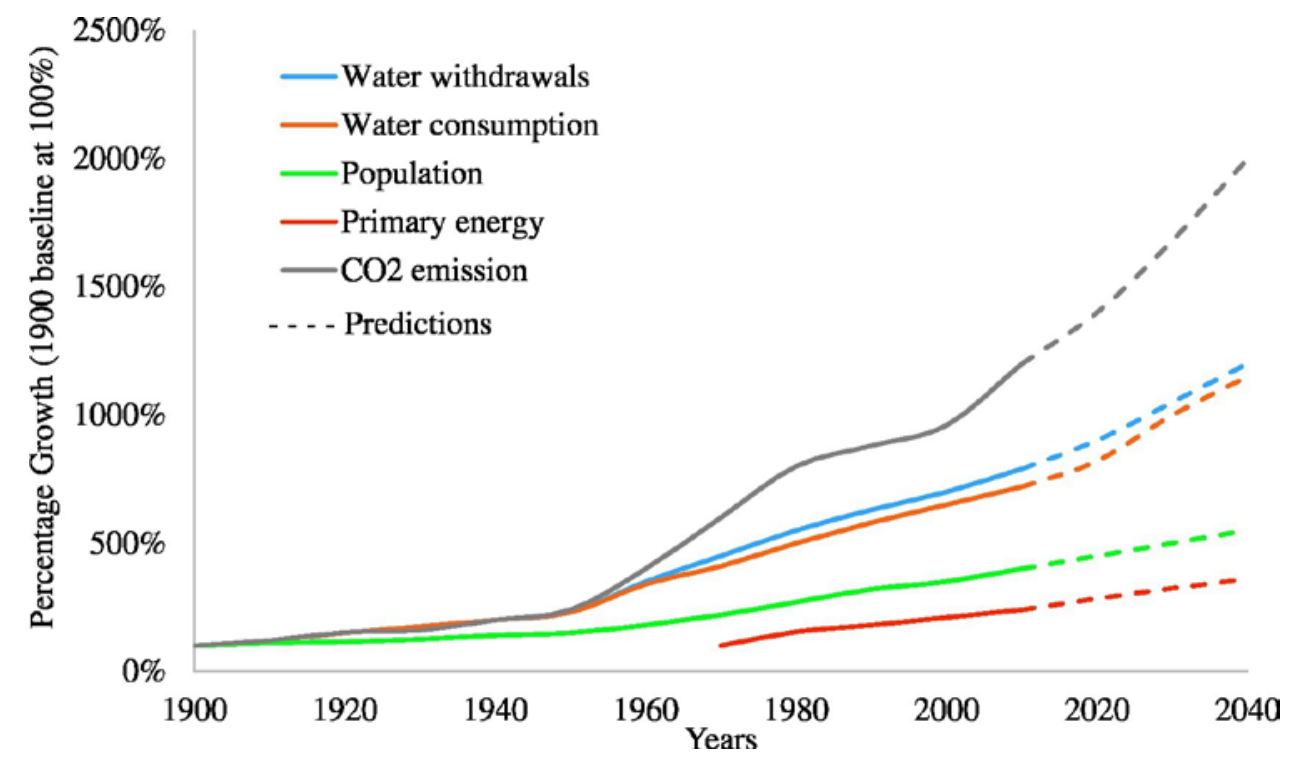

Figure 1. Water, population, primary energy, and carbon dioxide emission percentage growth rate, 1900-2040

Source: Shahzad (2017)

Desalination technologies, such as reverse osmosis or multiple-effect distillation, are costly and energy-intensive solutions to treating drinking water. According to the United Nations, the energy intensity for seawater desalination is $2.58-8.5 \mathrm{kWh} / \mathrm{m}^{3}$, as compared to $0.48 \mathrm{kWh} / \mathrm{m}^{3}$ for treating groundwater using conventional means for potable use (WWAP 2014). By 2030, desalination is anticipated to provide 54 billion $\mathrm{m}^{3}$ of treated water per year-a projected $40 \%$ growth from 2016 . The waste brine material generated by the desalination process poses additional challenges, as its disposal can adversely affect sensitive and unique island habitats and ecosystems, threatening their very existence as well as tourism benefits to the economy.

\subsubsection{Food}

Food security is a concern for islands, many of which, over time, have deemphasized local agriculture in favor of lower-cost imported foods. Though many islands are home to high-quality agricultural land, some of these nations have experienced:

... losses in preferential markets, inefficient production, slow traditional farming methods, soil erosion, slow technological advances, pests and diseases, shortage of inputs, and lack of appropriate and timely dissemination of weather and climate information to promote sustainable agriculture. (Trotman 2012)

Many islands have found it difficult to compete with food exports in a global economyemphasizing tourism and service industries instead — owing to limited land availability, high cost of land, and challenging environmental issues. Extreme weather events can hinder islands in their ability to produce food and rear livestock, creating another reason to rely on external supply chains to provide secure access to food for their inhabitants. But any path to food security must be weighed along with climate vulnerabilities and their associated impacts on crop selection and viability, coral reefs, beaches, and other land areas. While soil and land degradation have the potential to diminish 
land availability for food production, contributing to shortages and higher prices (National Intelligence Council 2017), degradation of coral reefs and beaches has the potential to dramatically reduce fish production (Toba 2009). Fisheries have remained active in island communities, but a great need exists to reestablish local agricultural practices and reduce reliance on food imports to establish greater resilience.

\subsubsection{Energy, Water, Food Nexus}

Energy, water, and food systems cannot be viewed in isolation. As described above, these systems are interconnected: energy is required to purify and distribute water and to cultivate and transport crops; water is needed to operate and maintain power systems and irrigate crops; food or land is required to generate energy and also impacts the quality and availability of water. A changing climate, population growth, and development trends make this EWF nexus increasingly important. Demands on these sectors will only continue to grow, highlighting the need for integrated, crosssectoral strategies that support islands' abilities to prepare for, withstand, and recover from extreme events (Clean Energy Solutions Center 2019).

Reliable EWF systems are the backbone of society, supporting public health and the economy. The socioeconomic importance of the EWF nexus should not be underestimated because:

... the interactions between chronic and acute stresses in local and regional food, water, and energy systems has led to failure of some governments ... to meet popular demands or address perceptions of unequal distribution of scarce resources, which might prompt future violent behavior by populations seeking redress. (National Intelligence Council 2017)

Whether before, during, or when recovering from a disaster, the EWF nexus is an increasingly important paradigm for the future of island communities.

\subsubsection{Hurricane Impacts and Lessons Learned}

In 2017, the U.S. territories of Puerto Rico and the U.S. Virgin Islands were hit by a series of hurricanes, including Category 5 Hurricane Maria. The same hurricanes made landfall on the U.S. mainland-primarily in Florida. Basic services, including electricity and water supplies, were restored to $99 \%$ of continental U.S. customers within 10 days of Hurricane Irma (Harris 2017). In contrast, over one third of Puerto Rico's residents remained without power for more than five months after Hurricane Maria - power was not fully restored for 11 months (Campisi and White 2018).

The two electric systems differ in many ways; however, some conclusions can be drawn as to the challenges faced specifically by islands in their recovery from an extreme event. Transportation of both materials and personnel are particularly challenging in post-disaster situations on islands. In the aftermath of Hurricane Irma, thousands of utility workers poured into the state of Florida from across the United States, bringing much-needed supplies and labor. In contrast, the U.S Government Accountability Office (GAO) noted that two of the most significant hindrances to restoring power in Puerto Rico (and the U.S. Virgin Islands) were logistics and the availability of supplies (Löw 2018).

In October 2018, after Typhoon Yutu struck the Northern Mariana Islands, 25\% of the population was displaced overnight, and more than 1,000 residents were left homeless for more than a month after landfall (Finnerty 2019). Additionally, an estimated 700-800 power poles and other distribution equipment had to be shipped in by the Federal Emergency Management Agency (FEMA) prior to starting any power-restoration activities (Mooney, Eilperin, and Chiu 2018). 
At the time of writing, the impacts of Hurricane Dorian on the Commonwealth of the Bahamas were still being assessed. Hurricane Dorian impacted the Bahamas from September 1-3, 2019. At peak strength, the Category 5 storm displayed sustained winds of up to 185 miles per hour (CDMA 2019). The flooding and 23-foot storm surges were so significant that one reporter noted, "large portions of the islands have become, for now, little more than extensions of the Atlantic" (Ward et al. 2019). By September 6, logistical challenges related to destroyed ports and inoperable airstrips left residents without power and with low food and water supplies (Ralpheson 2019). The lack of power hindered communications and medical services, and many of the smaller outlying islands had yet to be reached by rescue crews four days after the storm moved away from the island (Hughes and Garrison 2019). The long-term effects of this storm have yet to be seen. However, with significant destruction of infrastructure, it is likely that full recovery will take years. The United Nations estimated that $20 \%$ of the population - approximately 70,000 people - has been displaced and needs emergency housing, water, food, and other supplies (Altman 2019).

\subsection{Resilience}

At its core, resilience refers to the ability to anticipate, prepare for, and adapt to changing conditions and withstand, respond to, and recover rapidly from disruptions (Hotchkiss, Dane, and Komomua 2018). For island communities, building EWF resilience presents unique challenges. Most islands rely heavily on both imported food and energy sources. In turn, drinking water, food production, and their storage and/or conveyance depend on power generated from energy imports. As such, islands must create long-term, integrated strategies for boosting resilience in EWF systems.

The stranded nature of island power systems can limit generation, transmission, and distribution flexibility when restoring power. In larger national grids, power can be transmitted over great distances when a generation plant goes down. This allows distribution of power to begin (from an alternate plant) even if the local plant is not yet producing power. In contrast, island power systems often do not have the luxury of spatially diversified, large electricity-generation assets. The challenges of restoring power in island nations can also produce significant downstream effects. For example, island nations that rely heavily on electricity for pumping, treating, and distributing water may be unable to purify and distribute drinking water and treat sewage for its residents. This can have far-reaching health implications and can also negatively impact the agricultural, commercial, industrial, and tourism sectors. 


\section{Case Study: St. Eustatius' Solar and Energy Storage Park}

In the wake of extreme events, such as Hurricanes Irma and Maria, islands have reevaluated their strategies to prepare for and recover from energy, water and food system outages. With an interest in reducing exposure to risks from external supply chains and natural disasters, the island of St. Eustatius (Statia) constructed a first-of-its-kind solar and energy storage park focused on building EWF system resilience. The Statia Utility Company (STUCO) developed a unique solution to simultaneously address the island's need for reliable energy, community agriculture, and irrigation, using proven, integrated strategies that can be adopted by other islands to build resilience across the EWF nexus.

Statia is a small island in the Eastern Caribbean with a land area of approximately eight square miles and a population of nearly 3,200 inhabitants (Figure 2) (World Atlas 2019). Statia was previously part of the Netherlands Antilles and in 2010 became a special municipality of the Netherlands. Statia's economy is largely reliant on tourism and a crude oil fuel storage terminal located on the island. STUCO currently provides centralized electricity and drinking water for Statia.

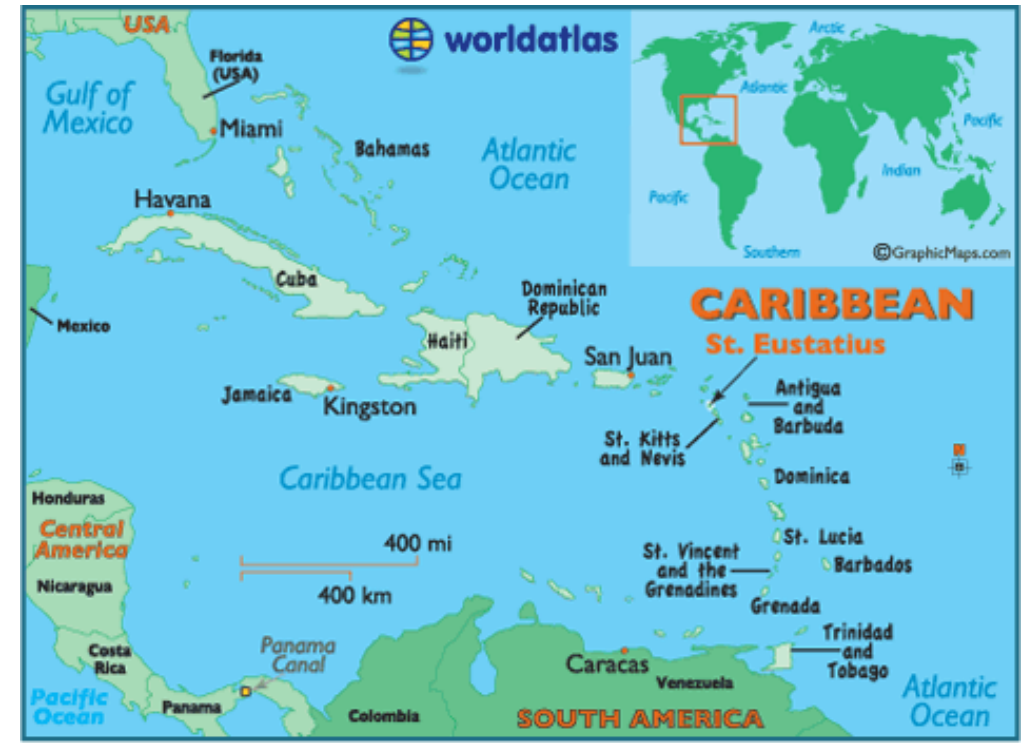

Figure 2. St. Eustatius

Source: World Atlas (2019)

Statia's power was historically provided by the St. Martin Power Company, which served St. Martin, Statia, and Saba using diesel generators. As a result of the dissolution of the Netherlands Antilles and the establishment of Statia as a special municipality, the responsibility for electricity generation, and all associated costs, were to be borne by the island's citizens. Supplying Statia with imported diesel fuel for energy generation was not financially viable or sustainable-with a $100 \%$ dependency on fossil fuel, more than 78\% of STUCO's income was used for fuel purchases alone. The Dutch government worked with Statia to develop a structural solution to address dependence on fossil fuel and energy costs, which emphasized the island's abundant solar resources. Statia's solar and energy storage park was born. To support the development of this project, Statia provided land for the solar park, and the Dutch government paid construction costs. The project was developed with the intent to ensure affordable electricity rates for community members. 
In 2016, Statia began construction of its $4.15-\mathrm{MW}_{\mathrm{p}}$ solar photovoltaic (PV) park, which was fully operational by the end of 2017 . The system provides sufficient power to meet $100 \%$ of daytime demand, using a 5.9-MWh battery storage system, a 4-MVA diesel generator capacity, and two 2.2MW grid-forming battery inverters (Figure 3) that allow diesel generators to be turned on and off without compromising the stability of the grid.

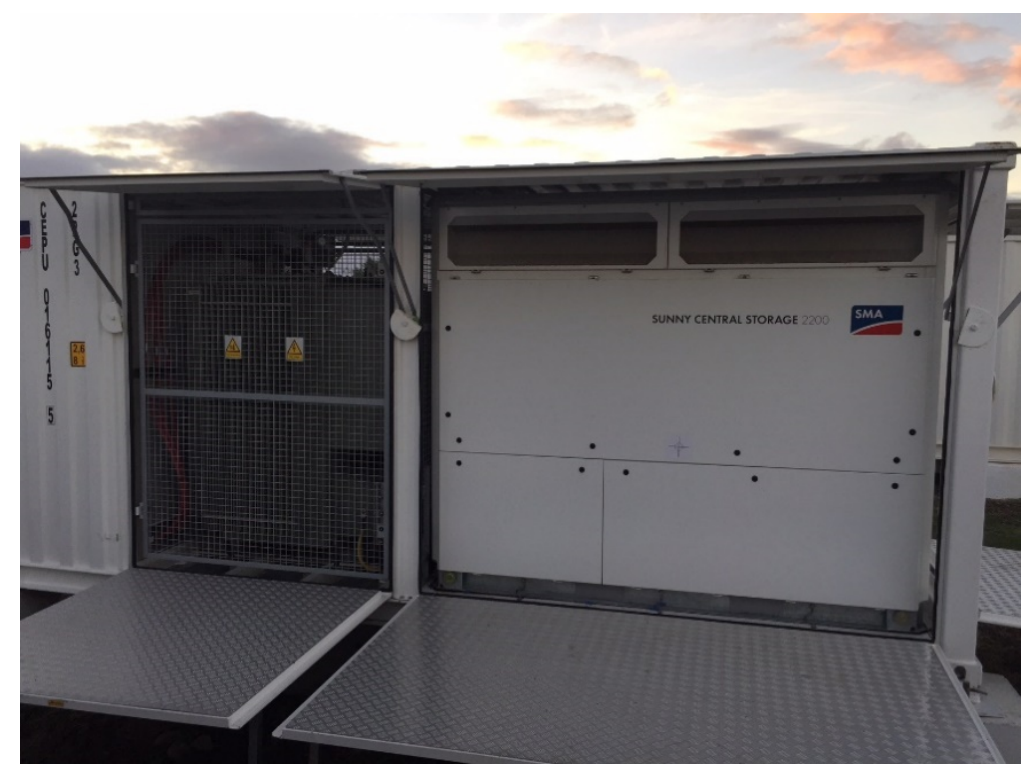

Figure 3. Grid-forming battery inverter

Photo by Jennifer Daw, NREL

The diesel generator fleet is automatically switched off during the daytime, while the two battery inverters take over automatically and form the grid for stable operation by providing a voltage source, frequency regulation, and spinning reserve. The inverters' control strategy combines power and energy management under consideration of system critical states (e.g., grid short circuit capability). This approach has dramatically reduced frequency variation during regular power system operations. The system has three separate battery storage units and uses an n-1 redundancy concept, while the system availability is maximized by partial operation patterns, particularly for the batteries and inverters (Figure 4). The system can effectively support the island's roughly 2-MW daytime energy needs, providing $40 \%-50 \%$ of Statia's electricity while saving roughly 1.7 million liters of diesel fuel and 4,500 metric tons of carbon dioxide per year (Figure 5) (Baars 2017). The benefits for STUCO's customers have been realized through a reliable and sustainable energy supply with less volatile tariffs. 


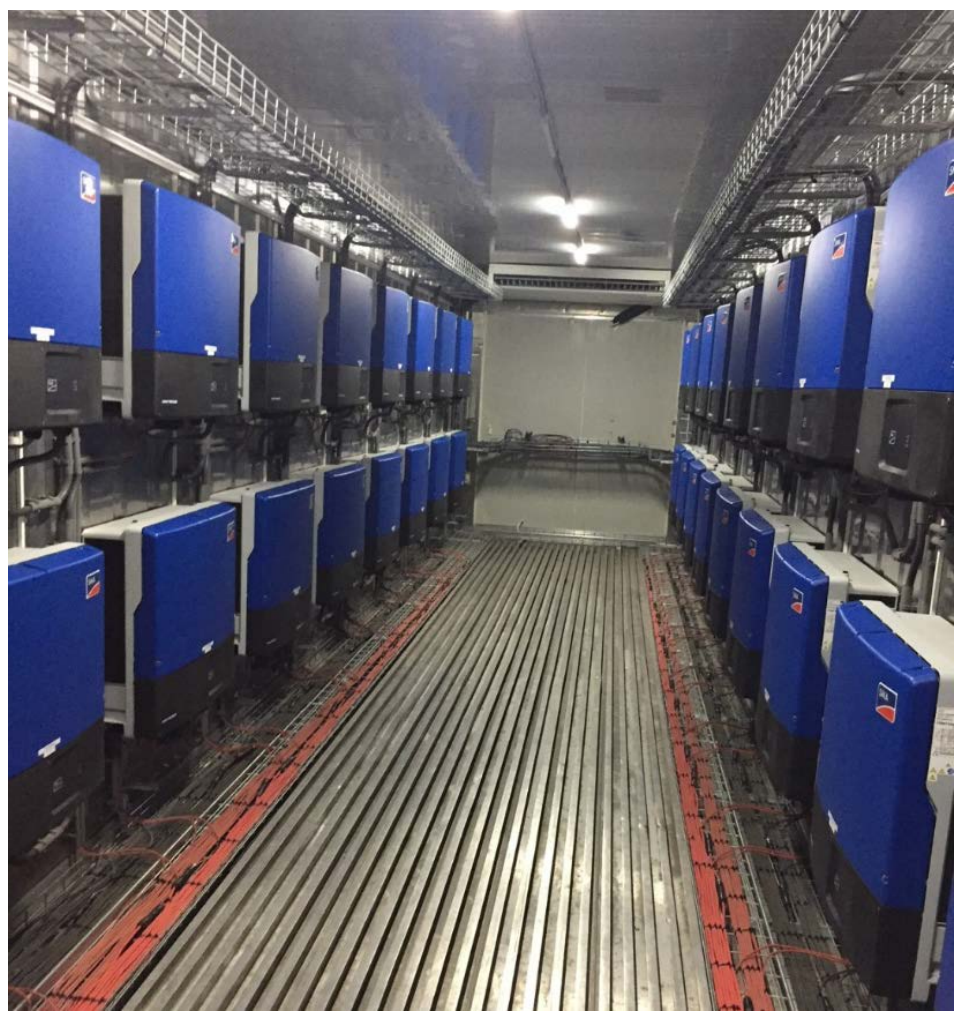

Figure 4. Battery bank

Photo by Jennifer Daw, NREL

FUEL SAVE CONTROLLER „DIESEL OFF MODE" DAYTIME WITHOUT DIESEL

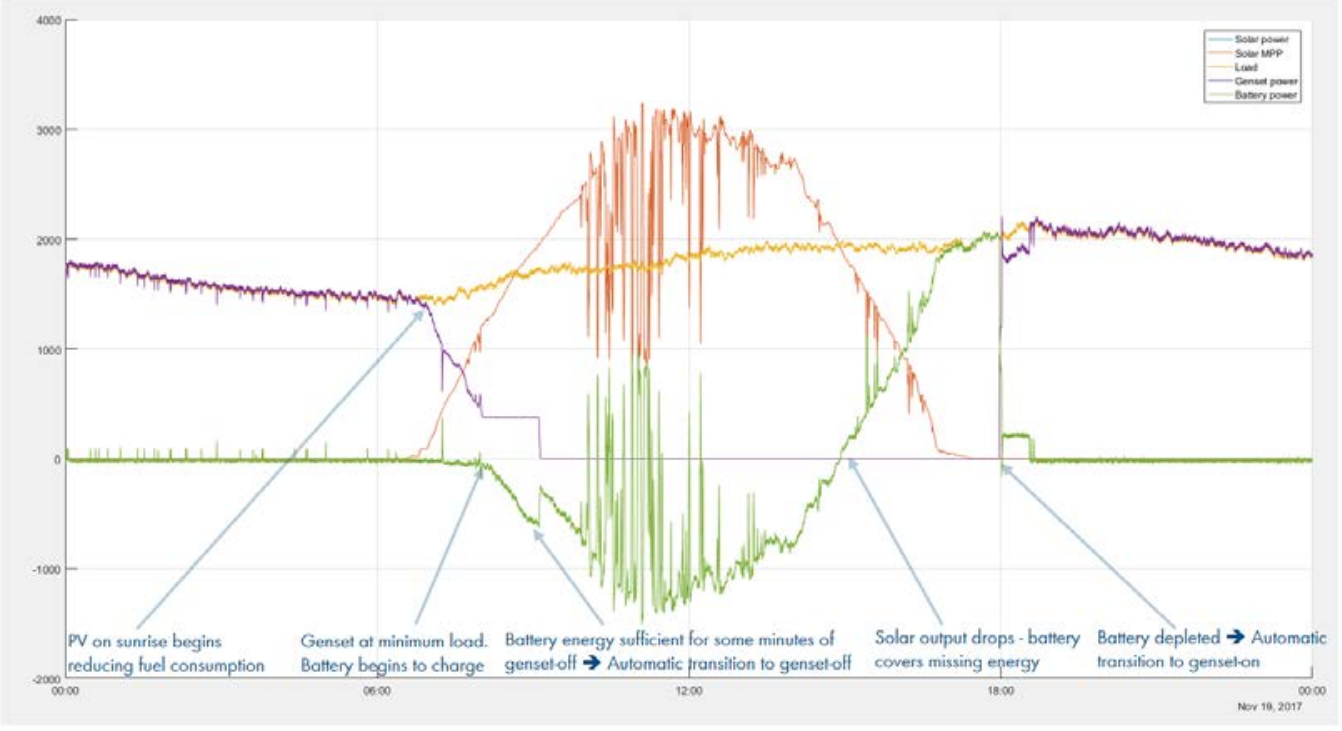

Figure 5. Typical day operations with diesel generators off

Source: SMA, STUCO (2018) 
An additional objective for the project's development was the ability to withstand extreme events, such as hurricanes, to which the island is susceptible. The PV array was designed with Category 5 hurricanes in mind, able to withstand winds of 157 miles per hour or more. Resilience measures included certifying the PV modules to withstand extreme wind forces (3,800 Pascal) and requiring mounting structures with vertical and horizontal resistance of roughly 5,000 kilonewtons. Statia took its resilience planning for the PV array a step further - while typically PV arrays in the Caribbean are mounted with a tilt of 15 degrees to maximize energy yield, Statia's array was mounted at 5 degrees. While this created a small reduction in the array's energy generation potential (a reduction of 1.04\%), lowering the angle reduced the amount of lift the panels would experience during a hurricane event. Reducing the tilt angle had the additional benefit of reducing land area required for the system, because it decreased spacing between the rows of PV panels from three meters to one meter (SMA, STUCO 2018).

The timing of this project coincided with Hurricane Irma, an extreme event, which hit the region in early September 2017. Statia's PV array was able to withstand Category 5 Irma's destructive power and provide continued access to energy and water systems during and after the event (Figure 6).

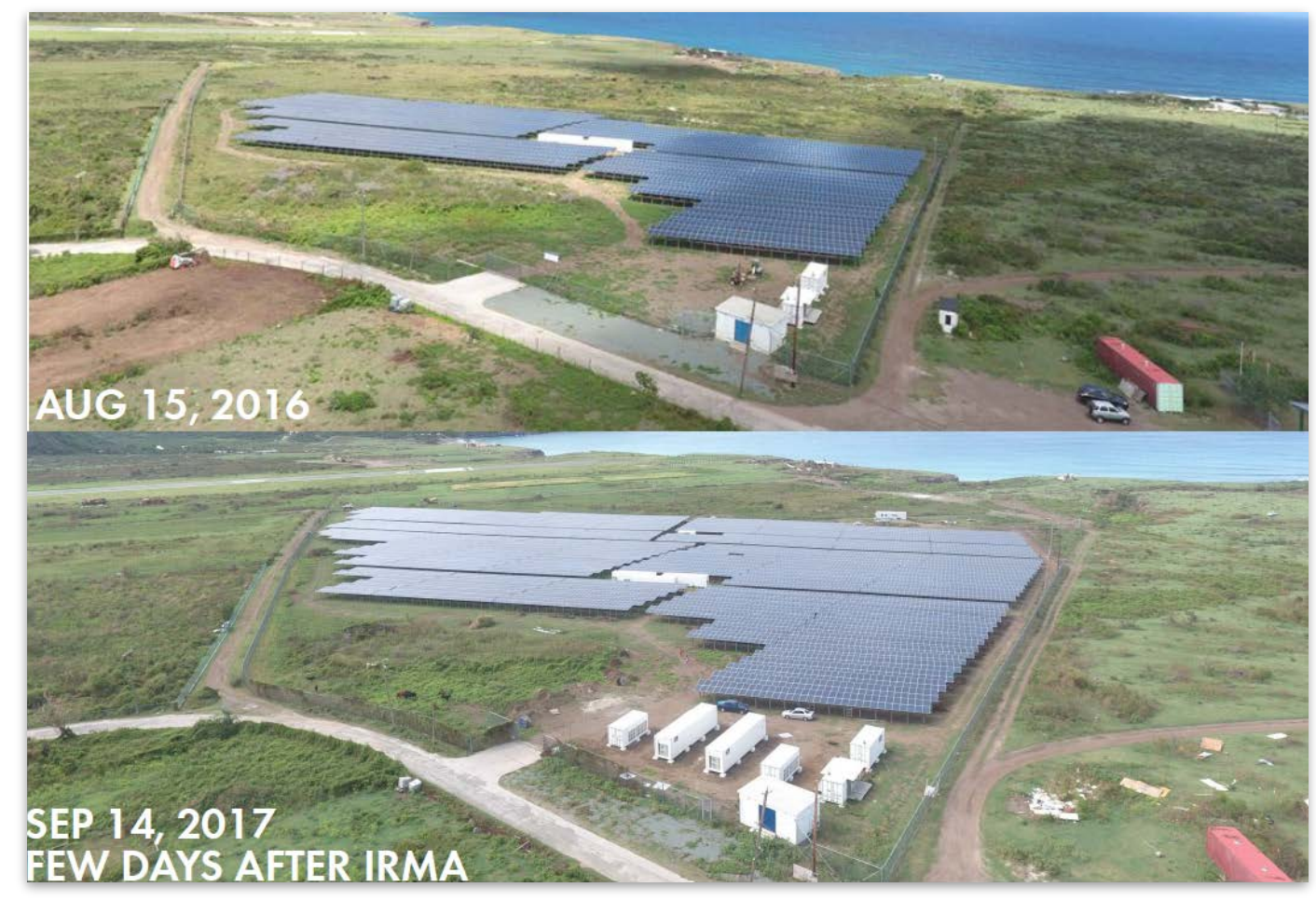

Figure 6. Statia solar and energy park before and after Hurricane Irma

Source: SMA, STUCO (2018)

STUCO's design of its solar and energy park also considered benefits to the community and environment. The PV panels were mounted two meters above the ground surface to allow for community gardens to be planted in the underlying space - meeting a growing demand for local agriculture on the island (Figure 7). This approach has been found to save both installation and operation and maintenance costs and improve PV system performance in studies conducted by the National Renewable Energy Laboratory (NREL) (Beatty et al. 2017; Macknick, Beatty, and Hill 2013). Typical construction of ground-mounted solar installations includes clearing and grubbing of soil and roots, topsoil stripping and stockpiling, land grading and leveling, soil compaction, and covering the underlying surface with gravel. While these practices make for convenient construction 
access and facility operations, they negatively impact habitats and have also been shown to increase construction costs. Studies have also shown increased runoff volumes when solar arrays had gravel or compacted ground underneath and have shown that runoff or peak discharge rates were not impacted when solar arrays had well-maintained grass (Cook and McCuen 2013).

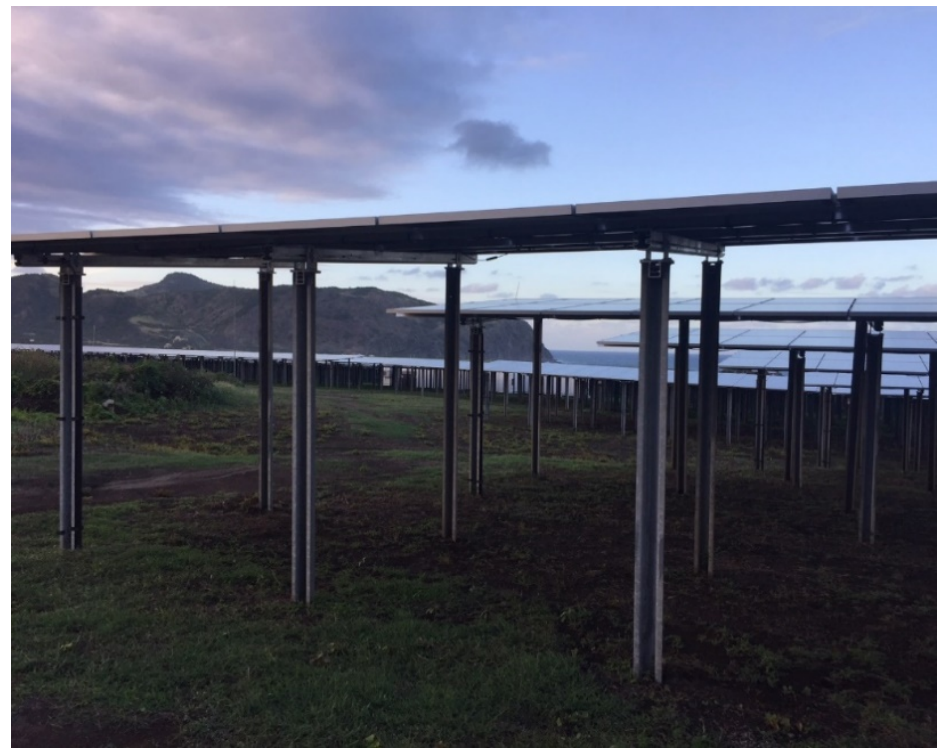

Figure 7. Novel mounting height of solar panels at Statia solar and energy park

Photo by Jennifer Daw, NREL

STUCO took the solar park a step further by designing the PV system to include a method to collect rainwater from intense and sporadic tropical rains, providing a much-needed fresh water source.

Gutters were mounted to the underside of the PV array to collect water from rainfall (estimated to be 2.6 million liters per year) and store it in an underground cistern (Figure 8). Water is used for panel cleaning and will be used for irrigation of the community garden when complete. This water storage solution will help the island have ready water supply for times of drought.

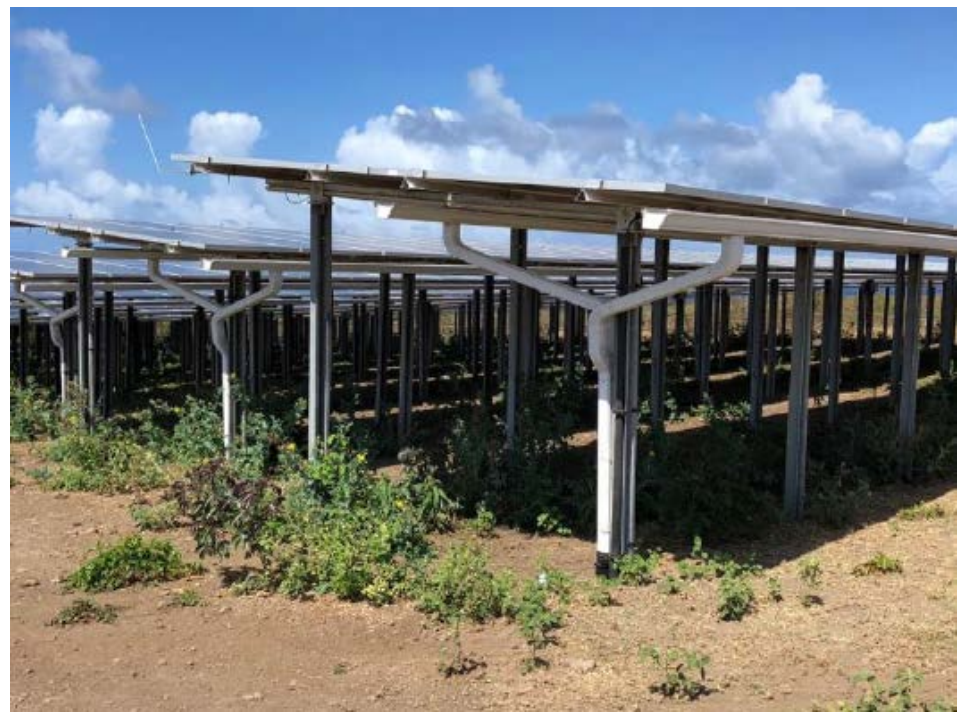

Figure 8. Rainwater-harvesting gutters mounted to PV array

Photo by: STUCO 


\section{Strategies to Build Island Resilience}

Statia's solar and energy storage park represents a successful, innovative, and sustainable solution for reducing exposure to the discontinuity of energy, water, and food supplies caused by extreme events. While the Statia solar and energy storage park is the first project of its kind in the Caribbean, the solution is scalable and can be adapted for islands in different contexts. Each island is unique, but islands of all sizes face similar challenges. There is an urgent need for islands to assess and prepare for the impact of extreme events by strengthening critical and exposed sectors, particularly energy, water, and food. This would include a comprehensive assessment of natural resources that can be leveraged to maintain supply to these sectors. In developing appropriate solutions to these challenges, it is important to involve all stakeholders including government, the private sector, and affected citizens.

\subsection{Energy}

As demonstrated above, islands have unique challenges - and, thus, opportunities - to enhance their resilience. Adoption of distributed energy resources (DER) including renewable energy and energy storage can increase spatial diversification of generation and reduce dependence on centralized generation plants. This reduces the vulnerability of the energy supply from a single event or a single critical location, increasing overall energy system resilience. DER systems can also represent redundant energy supply that can, with specific design considerations, supply energy when power from the main grid goes down. From an economic perspective, the development of a DER marketparticularly for small wind and PV - also creates local job markets for construction and maintenance.

DER systems are not immune to the forces of extreme events. Lessons learned from the 2017 and 2018 hurricane season demonstrate the need for resiliently designed DER systems. This includes designing racking systems to withstand hurricane-force wind, ensuring that systems are located outside of flood and inundation zones, using fasteners that will not loosen due to vibration from strong winds, removing debris from the site that could become windborne and damage panels, and ensuring proper pre-storm operation and maintenance checks of all equipment.

In addition to diversifying generation technology, islands can bolster resilience through operational changes. Programs that encourage energy efficiency and shifting demand can reduce overall stress on the power system and help stabilize power costs. Demand response programs can give power system operators increased flexibility to respond to minor outages or load shifts without increasing system stress or generation costs. These types of programs are most often implemented through policies, which can include the adoption of national building energy codes, new rate structures to incentivize behavior change or market participation, or incentive programs for energy-efficient design.

\subsection{Water}

Distributed generation can be used to support other EWF systems, such as water purification and delivery and wastewater treatment at a district or neighborhood scale, ensuring safe and reliable water access and sanitation and thus building community resilience. As noted previously, many islands are moving away from traditional methods of water treatment and toward more energyintensive solutions, such as desalination. A 2009 study noted that "energy usage accounts for about $44 \%$ of the cost of seawater desalination and contributes significantly to its environmental impact" (Eltawil, Zhengming, and Yuan 2009). The authors go on to note that use of renewable energy could significantly reduce the cost of delivered water. Additional studies (Li et al. 2018; Alkaisi, Mossad, and Sharifian-Barforoush 2017; Mentis et al. 2016; Chandrashekara and Yadav 2017; Gude 2016; Abdelkareem et al. 2017; Liu et al. 2017; Shahzad et al. 2017) draw the conclusion that renewable 
energy resources - primarily wind and solar — will be the future of water desalination around the world. This is largely due to the falling costs of renewable technologies and a move toward strategies to reduce emissions from fossil fuel plants. The financial and environmental impacts of imported fossil fuels, along with the cost competitiveness of renewable energy and energy storage technologies, have catalyzed growing interest in small-scale, high-efficiency integrated desalination systems that can operate exclusively on renewable sources, providing a sustainable solution to meet the growing demands for water in a resource-constrained world.

\subsection{Food}

While many islands have moved away from growing their own food, increasing food import costsas well as slowing globalization - are sparking a new generation of entrepreneurship at local levels, spurring more local agricultural production. This trend not only benefits the local economy, but also provides access to healthier perishable foods in lieu of processed foods with long shelf lives. This shift improves access to nutritious foods, supporting the health of community members.

Due to the small land area that is typical of islands, local agriculture often has higher production costs and limited economies of scale. This condition creates a stronger value proposition for niche products over traditional commodity crops. The future of island agriculture in many contexts is supported by sustainable farming practices that emphasize local resources and nonchemical inputs, while creating social and environmental benefits for the community. Sustainable agriculture includes practices intended to mimic natural ecological processes (e.g., minimizing tilling and water use, encouraging healthy soil by planting fields with different crops year after year and integrating croplands with livestock grazing, and avoiding pesticide use by nurturing the presence of organisms that control crop-destroying pests) (National Geographic 2019). A report on Caribbean agriculture notes that,

... since agricultural production in the islands is dominated by smallholder farmers who are undercapitalized, technologically limited, unaware of best practices and certification standards, and extremely vulnerable to climate change effects, a comprehensive policy framework should be established to support coordinated investment.

Additionally, accessible education must be provided to prospective farmers to reestablish local agriculture that is "tenable in the long run, minimize(s) dependence on expensive inputs, can supplement the fresh food and nutritional requirements of local consumers, and earn income from overseas markets once domestic needs have been fulfilled" (Tandon 2014).

The reestablishment of resilient local island agriculture would be remiss if it did not consider impacts on energy and water systems. According to Tandon (2014),

... there is a need to interpret sustainability from a more holistic point of view, recognizing the farmer as a producer and a manager of an ecological system that provides a large number of public goods and services as well, such as water, soil, landscape, energy, biodiversity, and recreation.

Through measures such as selecting appropriate crops for the climate and site conditions, using fitfor-purpose water for irrigation, optimizing irrigation strategies to accommodate both crop needs and energy availability in a water-efficient manner, making efficient use of energy, and using renewable energy sources for irrigation pumping, food processing, and transportation there is ample opportunity to establish food system resilience that also supports resilient energy and water systems. 


\section{Conclusions}

Islands are becoming increasingly vulnerable to climate-related threats, but also have unique challenges and opportunities to build long-term resilience. When developing strategies to build resilience, it is vital to consider social, economic, and environmental issues, as well as the interrelationship of the island's EWF systems. It is important that solutions complement each other, rather than solely benefiting one sector at the expense of others.

The importance of robust policy and regulatory frameworks cannot be underestimated when seeking to develop resilient EWF systems. Policy and regulatory environments can enable resilience by creating a framework that will strengthen systems, encourage diversity in infrastructure, develop resourceful operational practices, and formalize networks for mutual aid. These types of policy environments may also be necessary for developing funding and financing opportunities for enhancing resilience. Building resilience requires coordinated governance, policies, and frameworks that support integrated planning and decision making for EWF systems.

The challenges faced by islands create a unique environment for developing and testing novel approaches to resilience. The high cost of energy, water, and food allows new and emerging technologies space to compete with more traditional systems and incentivizes creativity in system planning and operation. Islands can thus serve as leaders in adaptation and resilience planning and can serve as examples for other climate-threatened jurisdictions. To truly build resilience, solutions must support the needs of the island's community, culture, unique resources, and long-term sustainability. 


\section{References}

Abdelkareem, Mohammad Ali, M. El Haj Assad, Enas Taha Sayed, and Bassel Soudan. "Recent progress in the use of renewable energy sources to power water desalination plants." Desalination 435 (November 2017): 97-113. https://doi.org/10.1016/j.desal.2017.11.018.

Ahmed Alkaisi, Ruth Mossad, and Ahmad Sharifian-Barforoush. "A Review of the Water Desalination Systems Integrated with Renewable Energy." Energy Procedia 110 (March 2017): 268-274. https://doi.org/10.1016/j.egypro.2017.03.138.

Ali, Muklis, and Fitri Wulandari. "UPDATE 2-Blackout on Indonesia's Java Due to Coal Disruption." Reuters. February 21, 2008. https://www.reuters.com/article/powerindonesia/update-2-blackout-on-indonesias-java-due-to-coal-disruptionidUSSP17318520080221.

Altman MJ. How the UN is responding to Hurricane Dorian's destruction. unfoundation.org Web site. https://unfoundation.org/blog/post/how-the-un-is-responding-to-hurricane-doriansdestruction/. Updated 2019. Accessed Sep 19, 2019.

Baars, Anke. "St. Eustatius: 100\% Solar Power in the Caribbean." SMA. December 14, 2017. https://www.sma-sunny.com/en/st-eustatius-100-solar-power-in-the-caribbean/.

Bailey, Ryan, Alise Beikmann, Maria Kottermair, Danko Taboroši, and John Jenson. "Sustainability of rainwater catchment systems for small island communities." Journal of Hydrology 557 (February 2018): 137-146. https://doi.org/10.1016/j.jhydrol.2017.12.016.

Beatty, Brenda, Jordan Macknick, James McCall, Genevieve Braus, and David Buckner. Native Vegetation Performance under a Solar PV Array at the National Wind Technology Center. NREL/TP-1900-66218. Golden, CO: NREL. May 2017. https://www.nrel.gov/docs/fy17osti/66218.pdf.

Bertsiou, M., E. Feloni, D. Karpouzos, and E. Baltas. "Water management and electricity output of a Hybrid Renewable Energy System (HRES) in Fournoi Island in Aegean Sea." Renewable Energy 118 (April 2018): 790-798. https://doi.org/10.1016/j.renene.2017.11.078.

CDEMA (Caribbean Disaster Emergency Management Agency), Major Hurricane Dorian: Situation Report No. 13 (As of 4:00 PM on September 14, 2019), September 2019, https://reliefweb.int/sites/reliefweb.int/files/resources/CDEMA_Situation_Report_13__Hurricane_Dorian_Sept_14_2019.pdf.

Chandrashekara, M., and Avadhesh Yadav. "Water desalination system using solar heat: A review." Renewable and Sustainable Energy Reviews 67 (January 2017): 1308-1330. https://doi.org/10.1016/j.rser.2016.08.058.

Chen, Qing, Yuan-Yuan Liu, Chang Xue, Yu-Ling Yang, Wei-Ming Zhang. "Energy selfsufficient desalination stack as a potential fresh water supply on small islands." Desalination 359 (March 2015): 52-58. https://doi.org/10.1016/j.desal.2014.12.010. 
Clean Energy Solutions Center. "Energy-Water-Food Nexus." Resource Library. https://cleanenergysolutions.org/resources/energy-water-food-nexus. Accessed August 19, 2019.

Cook, Lauren, and Richard McCuen. "Hydrologic Response of Solar Farms." Journal of Hydrologic Engineering 18, no. 5 (October 2011): 536-541.

https://ascelibrary.org/doi/10.1061/\%28ASCE\%29HE.1943-5584.0000530.

Corsini, Alessandro, and Eileen Tortora. "The influence of water desalination systems on load levelling of gen-set in small off-grid islands." Energy Procedia 142 (December 2017): 22302235. https://doi.org/10.1016/j.egypro.2017.12.623.

CNN DA. The airport on the island of Grand Bahama is 'a debris field' after Hurricane Dorian. CNN Web site. https://www.cnn.com/2019/09/05/us/bahamas-dorian-freeport-airport/index.html. Updated 2019. Accessed Sep 19, 2019.

CNN, Jessica Campisi and Jaquetta White. Finally, 11 months after Maria, power is restored in Puerto Rico -- except for 25 customers. CNN Web

site. https://www.cnn.com/2018/08/07/us/puerto-rico-maria-power-restored-wxc-trnd/index.html. Updated 2018. Accessed Sep 19, 2019.

EIA (U.S. Energy Information Administration). "Electric Power Monthly.” Last modified August 26, 2019. https://www.eia.gov/electricity/monthly/epm_table_grapher.php?t=epmt_5_6_a.

Eltawil, Mohamed, Zhao Zhengming and Liquiang Yuan. "A review of renewable energy technologies integrated with desalination system." Renewable and Sustainable Energy Reviews 13, no. 9 (December 2009): 2245-2262. https://doi.org/10.1016/j.rser.2009.06.011.

Energy Transition Initiative: Islands. "Energy Snapshot Puerto Rico.” DOE/GO-102015-4583. March 2015. https://www.nrel.gov/docs/fy15osti/62708.pdf.

Finnerty R. Recovery continues in Northern Mariana Islands after Super Typhoon Yutu. Hawaii Public Radio. November 29, 2018. Available from: https://www.hawaiipublicradio.org/post/recovery-continues-northern-mariana-islandsafter-super-typhoon-yutu\#stream/0.

Gnaneswar Gude, Veera. "Desalination and sustainability - An appraisal and current perspective." Water Research 89 (February 2016): 87-106.

https://doi.org/10.1016/j.watres.2015.11.012.

Gökçek, Murat. "Integration of hybrid power (wind-photovoltaic-diesel-battery) and seawater reverse osmosis systems for small-scale desalination applications." Desalination 435 (June 2018): 210-220. https://doi.org/10.1016/j.desal.2017.07.006.

Gómez-Gotor, Antonio, B. Del Río-Gamero, I. Prieto Prado, and A. Casanas. "The history of desalination in the Canary Islands." Desalination 428 (February 2018): 86-107. https://doi.org/10.1016/j.desal.2017.10.051. 
Harris D. Power restored to more than $99 \%$ of Floridians after Hurricane Irma.

orlandosentinel.com Web site. https:/www.orlandosentinel.com/news/breaking-news/os-poweroutage-numbers-hurricane-irma-20170920-story.html. Updated 2017. Accessed Sep 19, 2019.

Hills, Jeremy, Evanthie Michalena, and Konstantinos J. Chalvatzis. "Innovative technology in the Pacific: Building resilience for vulnerable communities." Technological Forecasting and Social Change 129 (April 2018): 16-26. https://doi.org/10.1016/j.techfore.2018.01.008.

Hotchkiss, Eliza, Alex Dane, and Connie Komomua. "Resilience Roadmap." National Renewable Energy Laboratory (NREL), 2018. https://www.nrel.gov/ resilience-planningroadmap/.

Hughes T, Garrison J. No way in, or out: Dorian's damage to Bahamas leaves survivors and rescue teams frustrated. USA Today. September 6, 2019. Available from: https://www.usatoday.com/story/news/nation/2019/09/06/hurricane-dorian-bahamasdeath-toll-rising-damage/2230109001/.

IDA (International Desalination Association). IDA Desalination Yearbook, Vol. Section 1. Market Profile 2015-2016.

Ioannidis, Alexis, and Konstantinos J. Chalvatzis. "Energy Supply Sustainability for Island Nations: A Study on 8 Global Islands." Energy Procedia 142 (December 2017): 3028-3034. https://doi.org/10.1016/j.egypro.2017.12.440.

Li, Zhenyu, Afreen Siddiqi, Laura Diaz Anadon, Venkatesh Narayanamurti. "Towards sustainability in water-energy nexus: Ocean energy for seawater desalination." Renewable and Sustainable Energy Reviews 82, no. 3 (February 2018): 3833-3847. https://doi.org/10.1016/j.rser.2017.10.087.

Liu, Jiahong, Chao Mei, Hao Wang, Weiwei Shao, and Chenyao Xiang. "Powering an island system by renewable energy — A feasibility analysis in the Maldives." Applied Energy (October 2017): 18-27. https://doi.org/10.1016/j.apenergy.2017.10.019.

Löw, Petra. "Hurricanes cause record losses in 2017-The year in figures." Munich RE. April 1, 2018. https://www.munichre.com/topics-online/en/climate-change-and-natural-disasters/naturaldisasters/2017-year-in-figures.html.

Luh, Jeanne, Sarah Royster, Daniel Sebastian, Edema Ojomo, and Jamie Bartram. "Expert assessment of the resilience of drinking water and sanitation systems to climate-related hazards." Science of The Total Environment 592 (August 2017): 334-44. https://doi.org/10.1016/j.scitotenv.2017.03.084.

Macknick, Jordan, Brenda Beatty, and Graham Hill. Overview of Opportunities for Co-Location of Solar Energy Technologies and Vegetation. NREL/TP-6A20-60240. Golden, CO: NREL. December 2013. https://www.nrel.gov/docs/fy14osti/60240.pdf. 
Mentis, Demetrios, George Karalis, Arthouros Zervos, Mark Howells, Constantinos Taliotis, Morgan Bazilian, Hoger Rogner. "Desalination using renewable energy sources on the arid islands of South Aegean Sea.” Energy 94 (January 2016): 262-72. https://doi.org/10.1016/j.energy.2015.11.003.

Mooney C, Eilperin J, Chiu A. Category 5 Typhoon Yutu devastates the Northern Marianas in worst storm to hit any part of U.S. since 1935. Washington Post. October 28, 2015. Available from: https://www.washingtonpost.com/energy-environment/2018/10/25/category-typhoondevastates-northern-marianas-worst-storm-hit-us-since/. Accessed Sep 19, 2019.

Morgan, Leanne, and Adrian D. Werner. "Seawater intrusion vulnerability indicators for freshwater lenses in strip islands." Journal of Hydrology 508 (January 2014): 322-27. https://doi.org/10.1016/j.jhydrol.2013.11.002.

National Geographic. "Sustainable Agriculture.” Accessed August 19, 2019.

https://www.nationalgeographic.com/environment/habitats/sustainable-agriculture/.

National Intelligence Council. Global Trends: Paradox of Progress. NIC 2017-001. January 2017. https://www.dni.gov/files/documents/nic/GT-Full-Report.pdf.

Nurse, Leonard, Roger McLean, John Agard, Lino Pascal Briguglio, Virginie Duvat-Magnan, Netatua Pelesikoti, Emma Tompkins, and Arthur Webb. "Small Islands." Climate Change 2014: Impacts, Adaptation, and Vulnerability. Part B: Regional Aspects. Contribution of Working Group II to the Fifth Assessment Report of the Intergovernmental Panel on Climate Change, 1613-1654. Cambridge, United Kingdom: Cambridge University Press, 2014.

Peñate, Baltasar, and Lourdes García-Rodríguez. "Current trends and future prospects in the design of seawater reverse osmosis desalination technology." Desalination 284 (January 2012): 1-8. https://doi.org/10.1016/j.desal.2011.09.010.

Prieto-Prado, I., B. Del Río-Gamero, A. Gómez-Gotor, and S.O. Pérez-Báez. "Water and energy self-supply in isolated areas through renewable energies using hydrogen and water as a double storage system.” Desalination 430 (March 2018): 1-14.

https://doi.org/10.1016/j.desal.2017.12.022.

Raphelson S. 'You can't stay here': Dorian leaves parts of the Bahamas uninhabitable. NPR.org Web site. https://www.npr.org/2019/09/06/758282750/you-can-t-stay-here-dorian-leaves-partsof-the-bahamas-uninhabitable. Updated 2019. Accessed Sep 19, 20

Romero-Ternero, Vicente, Lourdes García-Rodríguez, and Carlos Gómez-Camacho. "Thermoeconomic analysis of wind powered seawater reverse osmosis desalination in the Canary Islands.” Desalination 186, no. 1 (December 2005): 291-298.

https://doi.org/10.1016/j.desal.2005.06.006.

Shahzad, Muhammad Wakil, Muhammad Burhan, Li Ang, and Kim Choon Ng. "Energy-waterenvironment nexus underpinning future desalination sustainability." Desalination 413 (July 2017): 52-64. https://doi.org/10.1016/j.desal.2017.03.009. 
SMA (SMA Sunbelt Energy GmbH), and STUCO. (April 19, 2018) Solar and Energy Storage in the Caribbean the Case of St. Eustatius for Grid Resiliency and Diesel Free Operation."

Stone, Lauri, Burgess, Christopher. Solar under storm: Designing hurricane-resilient PV systems. Rocky Mountain Institute Web site. https://rmi.org/solar-under-storm-designing-hurricaneresilient-pv-systems/. Updated 2018. Accessed Sep 19, 2019.

Tandon, Nidhi. Strengthening Sustainable Agriculture in the Caribbean: A Guide for Project Support and Guidelines for a Policy Framework. Washington, D.C.: Multilateral Investment Fund. June 2014. http://competecaribbean.org/wpcontent/uploads/2015/02/Strengthening_Sustainable_Agriculture in-the-Caribbean_web.pdf.

Toba, Natsuko. "Potential Economic Impacts of Climate Change in the Caribbean Community." World Bank. 35 LCR Sustainable Development Working Group Paper No.32: 10. 2009.

Trotman, Adrian. "Climate Services and Agriculture in the Caribbean." Climate Exchange, 5962. Leicester, United Kingdom: Tudor Rose, 2012.

UN (United Nations). Report of the Global Conference on the Sustainable Development of Small Island Developing States, Bridgetown, Barbados, 25 April-6 May 1994 (United Nations publication, Sales No. E.94.I.18 and corrigenda), chap. I, resolution 1, annex II.

UNDP. "Responding to Climate Change in Small Island Developing States." September 2010. https://sustainabledevelopment.un.org/content/documents/960SIDS_Flyer_SEPT_27 09\%5b1\% 5d.pdf.

Ward J, Faiola A, Sullivan P, Achenbach J. Hurricane Dorian leaves terrible destruction in Bahamas as it rolls toward U.S. Washington Post. September 3, 2019. Available from: https://www.washingtonpost.com/national/hurricane-dorian-leaves-terrible-destruction-inbahamas-as-it-rolls-toward-us/2019/09/03/71dbebec-ce75-11e9-b29b-a528dc82154a story.html. Accessed Sep 19, 2019.

Wijayatunga, Priyantha, Len George, Antonio Lopez, and Jose Aguado. "Integrating Clean Energy in Small Island Power Systems: Maldives Experience." Energy Procedia, Renewable Energy Integration with Mini/Microgrid - Proceedings of REM2016, 103 (December 2016): 274-79. https://www.sciencedirect.com/science/article/pii/S1876610216314953?via\%3Dihub.

World Atlas. "Saint Eustatius." World Map. Accessed August 19, 2019. https://www.worldatlas.com/webimage/countrys/namerica/caribb/steustus.htm.

WWAP (United Nations World Water Assessment Programme). The United Nations World Water Development Report 2014: Water and Energy. UNESCO. 2014. https://unesdoc.unesco.org/ark:/48223/pf0000225741. 